\title{
Chemical Analysis of Palm Oil used in some Parts of Benue State, Nigeria
}

\author{
*Tor, Priscilla Ngunoon, Vesuwe, Rebecca Ngoholve, Oloruntoba, Sola Omodele, \\ Surma Nguamo \\ Department of Chemistry, Federal University of Agriculture, Makurdi
}

\begin{abstract}
The quality assessment of palm oil samples from four (4) locations across Benue State, Nigeria was conducted. From the analysis carried out, the free fatty acid value of Makurdi, Otukpo, Naka, and Ugbokolo oil samples were; $2.2 \%, 2.5 \%, 1.8 \%$ and $4.1 \%$ respectively. Apart from the Ugbokolo oil sample, the rest have acid values within the stipulated range. The iodine values were respectively $46.3 \mathrm{mg} / \mathrm{L}, 48.4 \mathrm{mg} / \mathrm{L}, 47.1 \mathrm{mg} / \mathrm{L}$ and $444.8 \mathrm{mg} / \mathrm{L}$ for Makurdi, Otukpo, Naka and Ugbokolo. Apart from Ugbokolo sample, the rest samples indicated that the oils contained the right proportion of fatty acids. The saponification values were; $191.5 \mathrm{mg} / \mathrm{g}$, $197.4 \mathrm{mg} / \mathrm{g} 204.2 \mathrm{mg} / \mathrm{g}$ and $206.6 \mathrm{mg} / \mathrm{g}$ for Makurdi, Otukpo, Naka and Ugbokolo towns respectively. Makurdi sample fell short of the stipulated range which may be due to the high amount of unsaponifiable. Ugbokolo sample was slightly higher than the stipulated range indicating that it has lower amount of unsaponifiable matter. While Otukpo and Naka samples gave good values The peroxide values were; $5.6 \mathrm{mg} / \mathrm{kg}, 11.7 \mathrm{mg} / \mathrm{kg}, 6.9$ $\mathrm{mg} / \mathrm{kg}$ and $9.1 \mathrm{mg} / \mathrm{kg}$ for Makurdi, Otukpo, Naka and Ugbokolo samples respectively. Apart from the oil obtained from Otukpo, the rest gave good results. The slightly higher value of Otukpo sample indicates that the oil is susceptible to oxidation. The moisture content of Makurdi sample was obtained as $0.0 \%, 4.5 \%$ for Otukpo sample, $5.0 \%$ for Naka sample and $2.6 \%$ for Ugbokolo sample. Apart from Makurdi, the rest were higher than the stipulated values. The value of the Makurdi sample clearly indicates that there was no dissolved water.
\end{abstract}

Keywords: oil palm, chemical analysis, saponification value, fatty acid

\section{INTRODUCTION}

The usage of Palm tree and its oil as an economic tree at the instance of the geometric decline in crude oil prices has currently taken a centre stage in global discuss. Palm oil is a neutral, non-polar, viscous substance that is liquid at ambient temperatures with both hydrophobic and lipophilic properties. It has a high carbon and hydrogen content and is usually flammable and surface active. Nigeria is the $5^{\text {th }}$ largest producer of oil palm worldwide with Indonesia topping the list [1].

In 2012, the annual revenue received by Indonesia and Malaysia together, the top two producers of palm oil, was $\$ 40$ billion. Between 1962 and 1982 global exports of palm oil increased from around half a million to 2.4 million tons annually and in 2008 world production of palm oil and palm kernel oil amounted to 48 million tons. According to FAO forecasts by 2020 the global demand for palm oil will double, and triple by 2050. As at 2011, Nigeria was the third-largest producer, with approximately 2.3 million hectares $\left(5.7 \times 10^{6}\right.$ acres) under cultivation. Until 1934 , Nigeria had been the world's largest producer. Both small and large-scale producers participated in the industry [2].

According to studies reported by the Center for Science in the Public Interest (CSPI), excessive intake of palmitic acid, which makes up 44 percent of palm oil, increases blood cholesterol levels and may contribute to heart disease. The CSPI also reported that the World Health Organization and the US National Heart, Lung and Blood Institute have encouraged consumers to limit the consumption of palmitic acid and foods high in saturated fat. According to the World Health Organization, evidence is convincing that consumption of palmitic acid increases risk of developing cardiovascular diseases, placing it in the same evidence category as trans fatty acids.

In response to negative reports on palm oil many food manufacturers transitioned to using hydrogenated vegetable oils in their products, which have also come under scrutiny for the impact these oils have on health [3-5]. A 2006 study supported by the National Institutes of Health and the USDA Agricultural Research Service concluded that palm oil is not a safe substitute for partially 
hydrogenated fats (trans fats) in the food industry, because palm oil results in adverse changes in the blood concentrations of LDL cholesterol and apolipoprotein B just as trans fat does. However, according to two reports published in 2010 by the Journal of the American College of Nutrition, palm oil is again an accepted replacement for hydrogenated vegetable oils and a natural replacement for partially hydrogenated vegetable oils, which are a significant source of trans-fats [6].

\section{Materials AND Methods}

\subsection{Sample Collection}

All chemicals used were of analytical grade. Phenolphthalein, iodine trichloride, ethanol, sodium thiosulphate solution and chlorform were products of British drug houses limited (BDH) UK. Hydrochloric acid, potassium iodide, diethylether and acetic acid were got from Sigma Aldrich. The oil samples were randomly collected from three most highly noticed producers of palm oil in Benue state; Otukpo, Ugbokolo, Naka and Makurdi town. The palm oils were properly kept in sealed plastic bottles kept from direct sunlight and heat for four (4) days [7].

\subsection{Procedure/Methods}

The following were the methods used during the analysis:

The method of analysis of association of analytical chemists (1984) was adopted for free fatty acid determination.

Pearson method was used for both peroxide and saponification value determinantions.

American society for testing and materials (ASTM) (1973) method was used for the determination of iodine value.

\subsection{Preparation of Reagents}

Alcoholic Potassium hydroxide solution $(0.1 \mathrm{M})$. The solution was prepared by dissolving $1.40 \mathrm{~g}$ of $\mathrm{KOH}$ pellets in $250 \mathrm{~mL}$ of methanol.

Phenolphthalein indicator (1\%). It was prepared by dissolving $1 \mathrm{~g}$ of Phenolphthalein in $100 \mathrm{mlL}$ of methanol.

$0.1 \mathrm{M} \mathrm{Na}_{2} \mathrm{~S}_{2} \mathrm{O}_{3} .5 \mathrm{H}_{2} \mathrm{O}$ was prepared by dissolving $24.80 \mathrm{~g}$ of sodium thiosulphate crystals in $1 \mathrm{dm}^{3}$ of distilled water.

$0.5 \mathrm{M}$ Alcoholic $\mathrm{KOH}$ was prepared by dissolving $7.0 \mathrm{~g}$ of $\mathrm{KOH}$ pellets in $250 \mathrm{~mL}$ of $95 \%$ ethanol.

$0.5 \mathrm{M} \mathrm{HCl}$ solution the solution was prepared by dissolving $18.23 \mathrm{~mL}$ of the acid in $1000 \mathrm{~mL}$ of water.

$10 \%$ potassium iodide solution: it was prepared by dissolving $10 \mathrm{~g}$ of $\mathrm{KI}$ in $100 \mathrm{~mL}$ of water.

$1 \%$ starch solution: $1 \mathrm{~g}$ of soluble starch was made into a paste using distilled water. The paste was then added to $100 \mathrm{~mL}$ of water mixed thoroughly and boiled for two minutes.

Wij's solution was prepared by dissolving $8 \mathrm{~g}$ of iodine tetrachloride in $250 \mathrm{~mL}$ glacial acetic acid. 9 $\mathrm{g}$ of iodine was dissolved in $300 \mathrm{~mL}$ of tetrachloromethane. The two solutions were then mixed and diluted to $1000 \mathrm{~mL}$ with glacial acetic acid [6-9].

\subsection{Chemical Analysis}

\subsubsection{Determination of Free Fatty}

The method of Analysis of the Association of Analytical Chemists (1984) was used.

$1 \mathrm{~g}$ of the oil sample was dissolved in $50 \mathrm{ml}$ of neutral solvent $(25 \mathrm{ml}$ of Diethylether and $25 \mathrm{ml}$ of $95 \%$ ethanol) in a conical flask. 2-3 drops of phenolphthalein indicator were added and the solution was titrated with $0.1 \mathrm{~m}$ alcoholic $\mathrm{KOH}$ until a pink colour which persisted for 15 seconds was obtained. The titre value of the $0.1 \mathrm{~m}$ alcoholic $\mathrm{KOH}$ was then used to calculate the Free Fatty Acid as percentage oleic acid [10].

$$
\text { Percentage free fatty Acid } \frac{T \times 282}{1000 \times 10 \mathrm{~g}} \times 100
$$

Where $\mathrm{T}=$ Titre value of alcoholic $\mathrm{KOH}$ used

$282=$ molecular weight of oleic acid

$\mathrm{g}=$ weight of oil sample used 


\subsubsection{Determination of Peroxide Value}

\section{Pearson's method was adopted}

$2 \mathrm{~g}$ of the oil sample was weighed in a clean boiling tube and while still hot; $1 \mathrm{~g}$ of powdered KI was added. $20 \mathrm{ml}$ of solvent mixture ( 2 volume glacial acetic acid +1 volume chloroform) was also added in the tube in the boiling water so that the liquid could boil for 30 seconds. The contents were quickly transferred into a flask containing $20 \mathrm{ml}$ of KI solution (5\%), the tube was washed twice with $25 \mathrm{ml}$ of water and titrated with. $0.002 \mathrm{M}$ Sodium thiosulphate solution using $1 \%$ starch solution. A blank titration was also carried out. A blank titration is one that is carried out exactly as described above but without a test sample (palm oil) [10].

The peroxide value was calculated as:

$$
\mathrm{P} . \mathrm{V}=\frac{T X M}{g} \times 10
$$

Where P.V=Peroxide Value

$\mathrm{T}=$ titre value of sodium thiosulphate solution

$\mathrm{M}=$ molarity of sodium thiosulphate solution

$\mathrm{g}=$ weight of oil sample used.

\subsubsection{Determination of Saponification Value}

\section{Pearson's method was adopted}

$2 \mathrm{~g}$ of the oil sample was weighed in a conical flask and $25 \mathrm{ml}$ of the alcoholic $\mathrm{KOH}$ solution was added. A reflux condenser was attached and the flask was heated in boiling water for 1 hour, shaking frequently, $1 \mathrm{ml}$ of phenolphthalein $(1 \%)$ solution was added and the alkalis was titrated with $0.5 \mathrm{~mL}$ $\mathrm{HCl}$ acid [11].. The endpoint colour change from pink to yellow which disappeared completely to colourless after a few minutes. A blank titration that is the one with same procedures with the above but without the oil sample was also carried out.

Saponification value is calculated as:

S.P. $=\frac{(b-a) \times 28.05}{g}$

Where S.P. $=$ Saponification Value

$\mathrm{b}=$ titre value of blank titration

$\mathrm{a}=$ titre value of sample titration

$\mathrm{g}=$ weight of the oil sample

$28.05=$ constant

\subsubsection{Determination of Iodine Value}

\section{The method by American Society for testing and Material (ASTM) (1973)}

$0.2 \mathrm{~g}$ of the oil sample was weighed in a conical flask $(250 \mathrm{ml}) 20 \mathrm{ml}$ of tetrachloromethane was added and the flask was swirled and the resulting mixture was kept in the dark for one hour. After one hour, $20 \mathrm{ml}$ of KI solution $(10 \%)$ was added followed by addition of $100 \mathrm{ml}$ of water. The solution was then titrated with $0.1 \mathrm{~m}$ sodium thiosulphate solution. The thiosulphate solution was added slowly from the burette into the conical flask while swirling until the yellow colour of the resulting solution was almost discharge. 3 drops of starch solution $(1 \%)$ were added and the thiosulphate solution added drop-wise until a blue-black colour of the starch-iodine complex was discharged [12].. A blank titration was also carried out.

The iodine value was then calculated using the equation below:

$$
\mathrm{I} . \mathrm{V}=\frac{(B-S) \times M \times 12.69}{G}
$$


Tor, Priscilla Ngunoon et al.

Where I.V= Iodine Value

$\mathrm{B}=$ titre value of blank titration

$\mathrm{S}=$ titre value of sample titration

$\mathrm{M}=$ Molarity of sodium thiosulphate

$\mathrm{G}=$ weight of oil sample used

$12.69=$ equivalent of Iodine

\subsubsection{Determination of Moisture Content}

A dry clean crucible was weighed $\left(\mathrm{w}_{1}\right), 5 \mathrm{~g}$ was added in the crucible to give weight $\left(\mathrm{w}_{2}\right)$, it was placed in an acid dry oven at $105^{\circ} \mathrm{C}$ for 4 hours. The moisture content was calculated as

$$
\text { M.C }=\frac{w 2-w 3}{W 2-W 1} \times 100
$$

Where M.C $=$ Moisture Content

$\mathrm{W}_{2}=$ weight of sample + crucible

$\mathrm{W}_{3}=$ weight after drying

$\mathrm{W}_{1}=$ weight of the empty crucible

\section{RESUlTS AND DiSCUSSION}

\subsection{Results}

The table below shows the acid value, iodine value, saponification value, peroxide value and moisture content for samples collected from A (Makurdi), B (Otukpo), C (Naka) and D (Ugbokolo).

Table3.1. Analysis of Palm Oil

\begin{tabular}{|l|c|c|c|c|}
\hline \multicolumn{5}{|c|}{ Sampling Point } \\
\hline PARAMETERS & A & B & C & D \\
\hline Iodine Value (mg/L) & 46.3 & 48.4 & 47.1 & 44.8 \\
\hline Peroxide Value (mg/kg) & 5.6 & 11.7 & 6.9 & 9.1 \\
\hline Acid Value (\%) & 2.2 & 2.5 & 1.8 & 4.1 \\
\hline Saponification Value (mg/g) & 191.5 & 197.4 & 204.2 & 206.6 \\
\hline Moisture Content (\%) & 0.0 & 4.5 & 5.0 & 2.6 \\
\hline
\end{tabular}

\subsection{Discussions}

\subsubsection{Results of Iodine Value}

According to Nigeria Industrial Standard (NIS), the range between $45 \mathrm{mg} / \mathrm{L}$ to $55 \mathrm{mg} / \mathrm{L}$ is quite acceptable [13]. From the results above, sample D fell short of the stipulated range but samples A, B, and $\mathrm{C}$ were within the given range. Since iodine value is a measure of the degree of unsaturation of oils, samples A, B, and C indicated that oil samples have normal values of unsaturated fatty acids comprising of oleic, linoleic acids respectively while sample D indicates so much of saturated fatty acids.

\subsubsection{Peroxide Value}

From the table of Standard (NIS), the maximum tolerable limit is $10 \mathrm{mg} / \mathrm{Kg}$ max in which sample B is slightly higher than the recommended value while sample A, C, and D fell within the stipulated values. Since peroxide value is the measure of the degree of oxidation of the oil, the higher value of sample B indicates that the oils are susceptible to oxidation [14].

\subsubsection{Results of Acid Value}

According to Nigeria Industrial Standard (NIS), the range is 3.5\% max is quite acceptable. From the results above, sample $\mathrm{D}$ is slightly higher than the recommended value while samples $\mathrm{A}, \mathrm{B}$, and $\mathrm{C}$ were within the range. The slight higher value of sample $\mathrm{D}$ could be attributed to poor storage or improper handling during processing [15-18]. The results obtained for samples A,B, and C may be as a result of their being freshly prepared and not stored for a longer time or they were well protected from harsh conditions such as moisture. 


\subsubsection{Saponification Value}

The accepted saponification value for palm oil is between $195 \mathrm{mg} / \mathrm{g}$ to $205 \mathrm{mg} / \mathrm{g}$. From the results above, sample A has a lower saponification value while sample D has slightly higher value. But samples B and C fell within the stipulated value indicate that esters of the fatty acids of low molecular weight were in right proportions.

The lower value for sample A may probably be as a result of high amount of unsaponifiable matters such as steroids and other impurities which cannot undergo saponification and hence help to lower the value of saponification. While the slightly higher value of sample D may be as a result of low amount of unsaponifiable matters present in the oil [19].

\subsubsection{Moisture Content}

From the table of Standard (NIS), the accepted value has $0.2 \%$ as maximum [20-23]. Samples B, C and $\mathrm{D}$ were higher than the recommended value. Only sample A fell within the range. The higher value of samples B, C and D indicates that there is high amount of water present in the oil sample, and this indicates high level of primary oxidation in the oil. While the value of sample A indicates that the water present in the oil has been removed completely.

\section{SumMary AND CONCLUSION}

The objective of this research work was to deduce the quality of palm oil consumed in the state from chemical analysis and to compare the result to the set standard by Nigeria Industrial Standard (NIS). Palm oil samples were collected from North bank market Makurdi, Otukpo, Naka and Ugbokolo. Analysis was carried out for the following parameters.

For Iodine value and acid value, samples A, B and C fell within the range while D fell short of the given range. For saponification value, sample A show a lower value while sample D shows higher value but samples $\mathrm{B}$ and $\mathrm{C}$ fell within the range. For moisture content, only sample A fell within the range while samples $\mathrm{B}, \mathrm{C}$ and $\mathrm{D}$ were higher than the recommended value. Finally, for peroxide value, samples A, C and D fell within the stipulated value while sample B was higher than the accepted value.

Since palm oil is very crucial for both local and industrial levels, significant attempt has to be made towards the control of the quality of palm oil.

\section{REFERENCES}

[1] Poku, K. (2002). "Origin of oil palm". Small-Scale Palm Oil Processing in Africa. FAO Agricultural Services Bulletin 148. Food and Agriculture Organization. ISBN 92-5-104859-2

[2] Alan, J. C. and Hamilton, R. J. (1989) Rancidity in foods, $4^{\text {th }}$ edition, Elsevier Science publishers limited, New York p.66-120

[3] ASTM (1973) Test for Iodine Value of Drying Oils and fatty acids American Society for Testing and Material.(20) p.748

[4] Aurand, L. W (1987) Food composition and analysis, AVI publishing Company, New York p.181, 184, 203-220

[5] Awan, J. A (1983) Elements of food spoilage and preservation. Published by Institute of Management and Technology, Enugu, Nigeria p.26

[6] Barness, A.C. (1925) Mechanical processes for the extraction of palm oil, $2^{\text {nd }}$ Special bulletin. Department of Agriculture, Nigeria p.8-9

[7] Gaman, P. M. and Sherrington K.B.(1990) The science of food, an introduction to food science, nutrition and microbiology, $3^{\text {rd }}$ edition, Oxford Pergamon Press Ltd. P.600.

[8] Godwin, T. W.(1980) The Biochemistry of the Carotenoids,1 Plant $2^{\text {nd }}$ edition) Sharpman and Hall, London p.2-3, 10-12

[9] Hartely, C.W.S. (1977) the oil palm, $2^{\text {nd }}$ edition, Longman group limited-London. p.1, 31, 37, 65, 693-700,703-717,742.

[10] Heller, Lorvaine (16 ${ }^{\text {th }}$ December, 2005). "Palm oil 'reasonable' replacement for trans fats. Say experts" food navigator. Retrieved $1^{\text {st }}$ March 2013. 
[11] Mathaus, Bertrand (2007). 'Use of palm oilnfor frying in comparism with other high stability oils". European Journal of Lipids Science and Technology. 109(4): 400-409. D10:10.1002 lejit.200600294

[12] Methods of Analysis of the Association of the Analytical Chemist, $4^{\text {th }}$ edition, (1984) p. 506-508

[13] Miraliakabari, H. (2007). Tree nut oils Chemical Characteristics Oxidation and Antioxidants. Library and Archives Canada= Bibliotheque et Archives Canada. P.31 ISBN 978-0-494-19381-5

[14] Morales, Alex (18 ${ }^{\text {th }}$ November 2010). "Malaysia has little room for expanding palm-oil production, minister says" Bloombery. Retrieved $1^{\text {st }}$ March 2013. Nigerian Industrial Standard (NIS)(1997).

[15] Obiahiagbon, F.C. (2012) "A review aspects of the African Oil Palm (Elaeis guineesis jacq)" (pdf). AmericanJournal of Biochemistry and Molecular Biology 2(3):1-

[16] Ononogbu, I.C. (1988) lipids and lipoproteins, new African publishing Co. Limited, Owerri.p. 201-203.

[17] Pearson, D. (1976). The chemical analysis of foods, $7^{\text {th }}$ edition, Chemical Publishing Co. New York p. 490, 492, 494-495

[18] Poku, Kwasi (2002). "Origin of oil palm" small-scale palm oil processing in Africa. FAO Agricultural Services bulletin 148. Food and Agriculture Organization. ISBN 92-5-104859-2.

[19] Scott-Thomas, Caroline (2012) "French firms urged to back away from no palm oil labels chains" food navigator Retrieved 7 March 2013

[20] Stuchlik, M; Zk, S (2002). "Vegetable lipids as components of functional foods" (pdf). Biomedical papers of the Medical Faculty of the University Palacky, Olomouc, Czechoslovakia 146 (2):3-10. doi: 10.5507/bp.2002.001.PMID 12572887.

[21] www.codex.org/standardfornamedvegetableoils.

[22] www.fas.usda.gov/psdonline

[23] Yahaya, Y. (2011). "World's largest biodiesel plant opens in Singapore" the Jakarta Globe. Retrieved 25 February 2013. 